\title{
Microstrip Patch Antenna with Defected Ground Structure for Bandwidth Enhancement
}

\author{
Gurpreet Singh \\ Research Scholar (M.Tech.) \\ SBSSTC, Ferozepur
}

\author{
Rajni \\ Assoc. Prof. \\ SBSSTC, Ferozepur
}

\author{
Ranjit Singh Momi \\ H.O.D. (ECE Deptt.) \\ YRS Polytechnic, Moga
}

\begin{abstract}
In this paper, a new Defected Ground Structure (DGS) consisting of I-shape slot in ground has been presented to enhance the bandwidth of the Microstrip Patch Antenna (MPA). The parameters such as Bandwidth, Return loss and VSWR are much improved in proposed antenna than simple MPA without defected ground structure. Finite Element Machine (FEM) based High Frequency Structure Simulator (HFSS) software Version-13.0 is used to obtain the performance parameters of the proposed antenna. A comparison is also shown for the proposed antenna with the antenna structure without defect. The proposed antenna resonates in C-band at frequency of $6.0718 \mathrm{GHz}$ with bandwidth of $132.3 \mathrm{MHz}$. A very good return loss of -46.75 $\mathrm{dB}$ is obtained for I-Shaped Defected Ground Structure (DGS). Also I-shaped DGS in the ground plane found to give a size reduction of about $5 \%$.
\end{abstract}

\section{General Terms}

Bandwidth (B.W.), Voltage Standing Wave Ratio (VSWR), return loss $\left(\mathrm{S}_{11}\right)$, gain and directivity.

\section{Keywords}

Defected Ground Structure (DGS), Microstrip Patch Antenna (MPA).

\section{INTRODUCTION}

Recently, a growing demands of microwave and wireless communication systems in various applications resulting in an interest to improve antenna performances. Therefore, the selection of microstrip antenna is suitable to apply at various fields such as telecommunication, medical application, satellite and military system. However, microstrip antenna has its inherent shortcomings such as narrow bandwidth, typically $5 \%$ of centre frequency and half space radiation [1]. Many kind of miniaturization techniques, such as using of dielectric substrate of high permittivity [2], slot on the patch, DGS at the ground plane or a combination of them have been proposed and applied to microstrip patch antennas.

Conformal microstrip antennas are applied for a wide variety of higher frequency, such as the cylindrical microstrip antenna, has been paid more attention by many researchers [35], which can reduce the size, widen the radiation beam. The surface wave restricts the wide use of microstrip antenna, electromagnetic bandgap (EBG) or photonic bandgap (PBG) structure is a method to reduce the surface waves, which exhibit band-gap feature [6] too. EBG has been applied in the field of antenna to improve the performance of antenna [712], such as suppression of surface wave propagation, increasing the gain of antenna and improving the radiation pattern by inserting the EBG structure into the substrate [1315]. However, in implementing EBG, a large area is needed to implement the periodic patterns and it is also difficult to define the unit element of EBG.

Defected ground structure (DGS) has similar microwave circuit properties as EBG, it can also modify guided wave properties to provide a band-pass or band-stop like filter and can easily define the unit element. The geometry of DGS can be one or few etched structure which is simpler and does not need a large area to implement it [16]. DGS structure disturbs the shield current distribution in the ground plane [17], [18], which influences the input impedance and current flow of the antenna.

Many shapes of DGS slot have been studied in planar microsrip antenna designs [19-21], which provides many good performances such as size reduction (resonant frequency lower), impedance bandwidth enhancement (quality factor lower) and gain increasing. The compact, broadband microstrip antenna with defective ground plane has been realized in [22]; the impedance bandwidth of the proposed antenna could reach about 4.3 times that of the conventional microstrip antenna. Several slots are embedded in the ground of the microstrip antenna so that the size is reduced, the impedance band and gain is enhanced [20]. By utilizing a slotload technique [22], the microstrip slot antenna excites two resonant frequencies. By combining with a defective ground plane, the bandwidth is augmented and the resonant frequency is lowed simultaneously.

In this paper work, a notable ground structure named defected ground structure (DGS) has recently been investigated and found to be a simple and effective method to reduce the antenna size. Proposed antenna design incorporates I-Shaped Defected Ground Structure in ground plane. Etching this DGS underneath the simple microstrip feedline, impedance bandwidth broadening can be obtained.

\section{ANTENNA DESIGN}

Both MPA and proposed antennas are designed on Rogers RT/Duroid $5880(\mathrm{tm})$ substrate with thickness $\left(\mathrm{h}_{\mathrm{s}}\right)$ of 0.794 $\mathrm{mm}$ having relative permittivity $\left(\varepsilon_{\mathrm{r}}\right)$ of 2.2 . The patch has the dimensions of $15.236 \mathrm{~mm} \times 25.236 \mathrm{~mm}$ with height $\left(\mathrm{h}_{\mathrm{p}}\right)$ of $0.05 \mathrm{~mm}$. The ground has the dimensions of $20 \mathrm{~mm} \times 30 \mathrm{~mm}$ with height $\left(\mathrm{h}_{\mathrm{g}}\right)$ of $0.05 \mathrm{~mm}$. Antenna is excited with microstrip feed having characteristics impedance of $50 \Omega$. The feed has dimension of $2.382 \mathrm{~mm} \times 2.2 \mathrm{~mm}$ with height $\left(\mathrm{h}_{\mathrm{f}}\right)$ of $0.05 \mathrm{~mm}$. The complete geometry of simple MPA is shown in Fig. 1.

In order to improve the Bandwidth and Return loss, ground is defected with I-Shape slot. The width of slot along Y-axis is 3 $\mathrm{mm}$ and the length of slot along $\mathrm{X}$-axis is $10 \mathrm{~mm}$ as shown in Fig. 2. Also this slot made on ground helps in the reduction of overall weight and size of proposed antenna. 


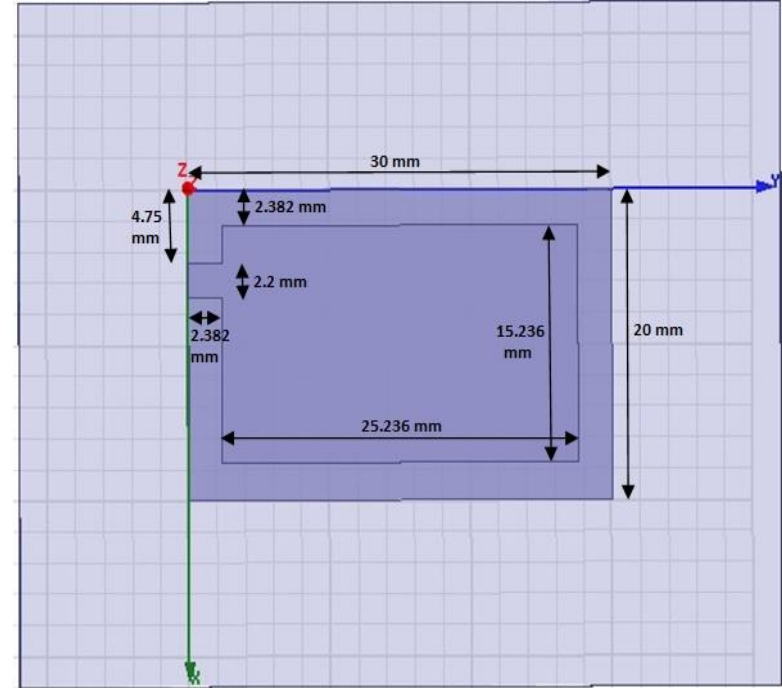

Fig 1: Geometry of simple MPA antenna

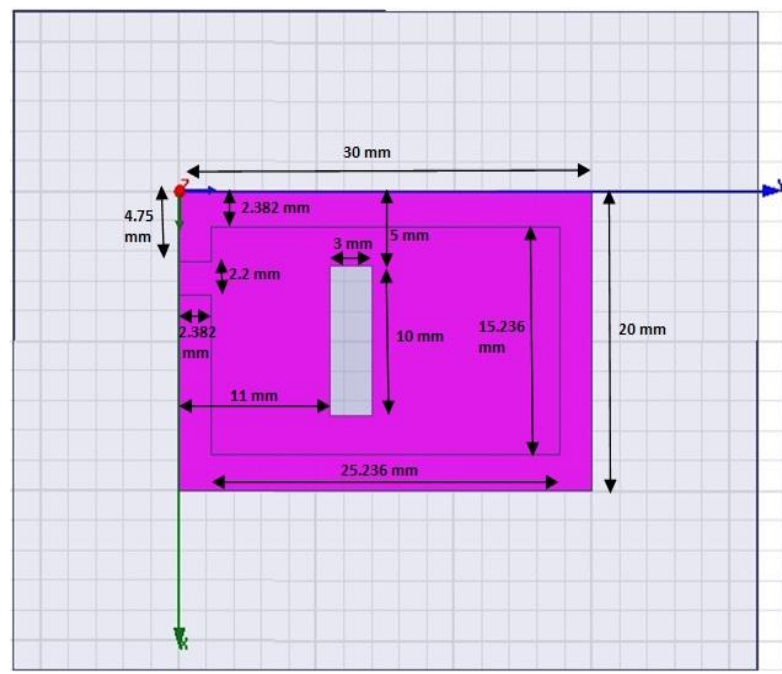

Fig 2: Geometry of G-shaped DGS antenna

Table 1 shows some common design parameters or specifications for both antennas i.e. simple MPA and I-slot DGS antenna.

Table 1. Common design specifications for both antennas

\begin{tabular}{|l|c|c|}
\hline $\begin{array}{l}\text { Sr. } \\
\text { No. }\end{array}$ & Specifications & $\begin{array}{c}\text { Dimensions (mm) } \\
\text { Values }\end{array}$ \\
\hline 1. & Ground $\left(\mathrm{L}_{\mathrm{g}} \times \mathrm{W}_{\mathrm{g}} \times \mathrm{h}_{\mathrm{g}}\right)$ & $20 \times 30 \times 0.05$ \\
\hline 2. & Substrate $\left(\mathrm{L}_{\mathrm{s}} \times \mathrm{W}_{\mathrm{s}} \times \mathrm{h}_{\mathrm{s}}\right)$ & $20 \times 30 \times 0.794$ \\
\hline 3. & Patch $\left(\mathrm{L}_{\mathrm{P}} \times \mathrm{W}_{\mathrm{P}} \times \mathrm{h}_{\mathrm{p}}\right)$ & $15.236 \times 25.236 \times 0.05$ \\
\hline 4. & Feed $\left(\mathrm{L}_{\mathrm{f}} \times \mathrm{W}_{\mathrm{f}} \times \mathrm{h}_{\mathrm{f}}\right)$ & $2.382 \times 2.2 \times 0.05$ \\
\hline 5. & $\begin{array}{c}\text { Permittivity of substrate } \\
\text { material "Rogers } \\
\text { RT/Duroid } 5880 \text { tm" }\left(\varepsilon_{r}\right)\end{array}$ \\
\hline
\end{tabular}

The Proposed antenna resonates at frequency $\left(\mathrm{f}_{\mathrm{r}}\right)$ of 6.0718 $\mathrm{GHz}$. The resonant frequency, also called the center frequency, is selected as the one at which the return loss is minimum. For a specific resonant frequency $\left(f_{r}\right)$ and dielectric constant of substrate $\left(\varepsilon_{\mathrm{r}}\right)$, the width $(\mathrm{W})$, length (L) of patch of MPA are expressed as follows:

$$
\begin{aligned}
& \mathrm{W}=\frac{1}{2 \mathrm{f}_{\mathrm{r}} \sqrt{\mu_{0 \varepsilon_{0}}}} \sqrt{\frac{2}{\varepsilon_{r}+1}} \\
& \mathrm{~L}=\mathrm{Le}-\Delta \mathrm{L}
\end{aligned}
$$

where, $\mathrm{L}_{\mathrm{e}}$ and $\Delta \mathrm{L}$ are the effective and extended Length of patch and are expressed as:

$$
\begin{aligned}
& \mathrm{Le}_{\mathrm{e}}=\frac{c}{2 f_{0 \sqrt{\varepsilon_{e}}}} \\
& \Delta \mathrm{L}=0.412 \mathrm{~h} \frac{\left(\varepsilon_{e}+0.3\right)\left(\frac{W}{h}+0.2664\right)}{\left(\varepsilon_{e}-0.258\right)\left(\frac{W}{h}+0.8\right)}
\end{aligned}
$$

where, $\varepsilon_{\mathrm{e}}$ is the effective dielectric constant of substrate and is expressed as:

$$
\varepsilon_{e}=\frac{\varepsilon_{r}+1}{2}+\frac{\varepsilon_{r}-1}{2}\left[1+12 \frac{h}{W}\right]^{\frac{-1}{2}}
$$

Similar results for finite and infinite ground plane can be obtained if the size of the ground plane is greater than the patch dimensions by approximately six times the substrate thickness all around the periphery [14]. Hence, for this design, the ground plane dimensions would be given as:

$$
\begin{aligned}
& \mathrm{Lg}=6 \mathrm{~h}+\mathrm{L} \\
& \mathrm{Wg}_{\mathrm{g}}=6 \mathrm{~h}+\mathrm{W}
\end{aligned}
$$

where, " $h$ " is the height of substrate. $\mathrm{L}_{\mathrm{g}}$ and $\mathrm{W}_{\mathrm{g}}$ are length and width of ground plane respectively.

In order to improve the Bandwidth and Return loss, ground is defected with I-Shape slot. Also this slot made on ground helps in the reduction of overall weight and size of proposed antenna.

\section{RESULTS AND DISCUSSIONS}

Finite Element Machine (FEM) based High Frequency Structure Simulator (HFSS) software Version-13.0 package is used to obtain the performance parameters of the proposed antenna.

\subsection{Return loss $\left(\mathrm{S}_{11}\right)$ and bandwidth}

It is evident from Fig. 3 that when I-shaped defect in ground plane is introduced, the proposed antenna resonates in C-band at resonant frequency $\mathrm{f}_{\mathrm{r}}=6.0718 \mathrm{GHz}$. A very good return loss of $-46.75 \mathrm{~dB}$ at $\mathrm{f}_{\mathrm{r}}=6.0718 \mathrm{GHz}$ is obtained for this structure. At this resonant frequency, it gives a maximum bandwidth of $132.3 \mathrm{MHz}$ (i.e. $\mathrm{MX}_{1}-\mathrm{MX}_{2}$ ).

While the Fig. 4 depicts that MPA without slotting in ground also resonates in the $\mathrm{C}$-band but at resonant frequency $\mathrm{f}_{\mathrm{r}}=$ 6.2051 GHz. The bandwidth of the microstrip patch antenna with same dimensions as mentioned above but without slotting is $126.2 \mathrm{MHz}$ at $\mathrm{f}_{\mathrm{r}} 6.2051 \mathrm{GHz}$. The value of return loss $\left(\mathrm{S}_{11}\right)$ obtained from MPA is $-27.72 \mathrm{~dB}$. 


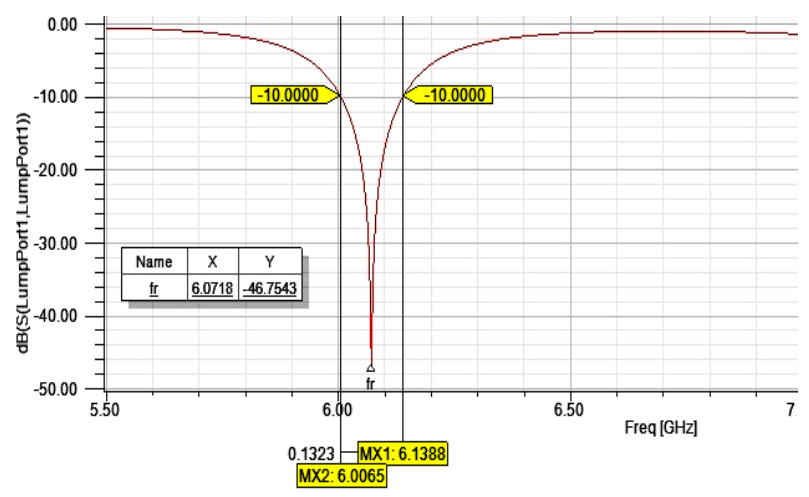

Fig 3: Return loss $\left(\mathbf{S}_{11}\right)$ of I-slot DGS antenna

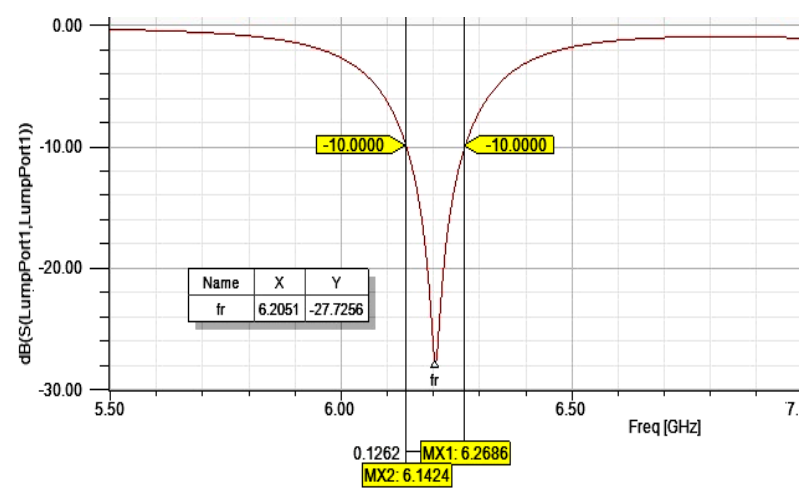

Fig 4: Return loss $\left(\mathrm{S}_{11}\right)$ of MPA

Thus it has been concluded that with I-Shape DGS, the bandwidth of the microstrip patch antenna (MPA) can be increased by $6.1 \mathrm{MHz}$ (i.e. $132.3 \mathrm{MHz}-126.2 \mathrm{MHz}=6.1$ $\mathrm{MHz})$.

\subsection{VSWR}

Fig. 5 shows VSWR plot of the proposed antenna. At frequency of $6.0718 \mathrm{GHz}$, the VSWR is 1.009 . As the value of VSWR is approximately equal to 1 at resonant frequency $\left(f_{r}\right)$, proposed antenna results in perfect impedance matching.

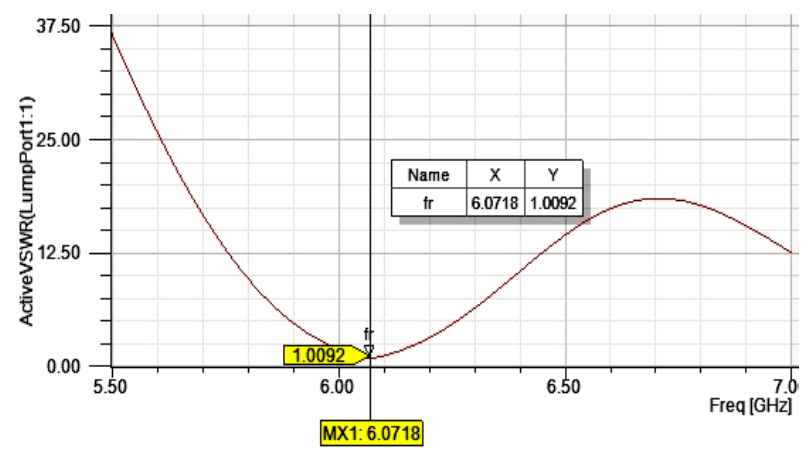

Fig 5: VSWR Plot of I-Shaped Antenna

While the VSWR, in case of simple MPA i.e. without defected ground at resonating frequency $\mathrm{f}_{\mathrm{r}}=6.2051 \mathrm{GHz}$ is 1.085 as shown in Fig. 6.

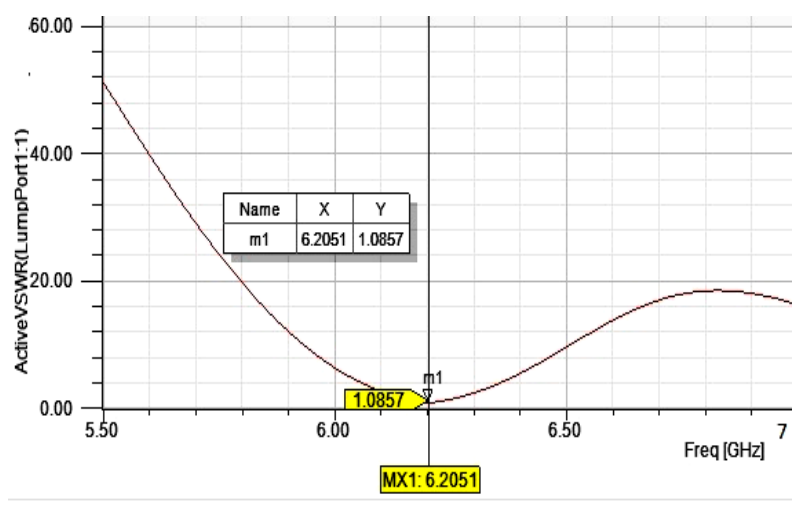

Fig 6: VSWR Plot of MPA

\subsection{Total gain}

Fig. 7 shows the Polar plot for gain, obtained from I-shaped DGS Antenna. The Total Gain provided by proposed antenna at $\mathrm{f}_{\mathrm{r}} 6.0718$ is $7.91 \mathrm{~dB}$.

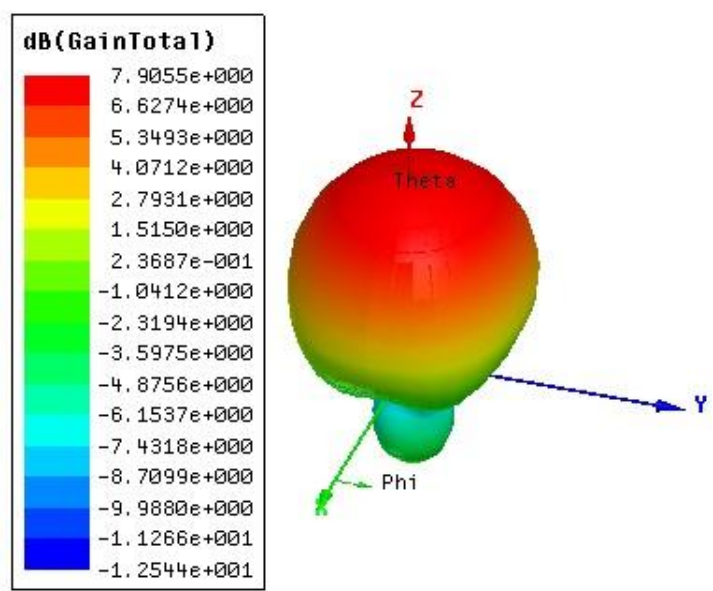

Fig 7: 3D Polar Plot of Total Gain of I-Slot DGS antenna

While the obtained gain, in case of MPA i.e. without defected ground at resonant frequency $\mathrm{f}_{\mathrm{r}}=6.2051 \mathrm{GHz}$ is $7.96 \mathrm{~dB}$ as shown in Fig. 8.

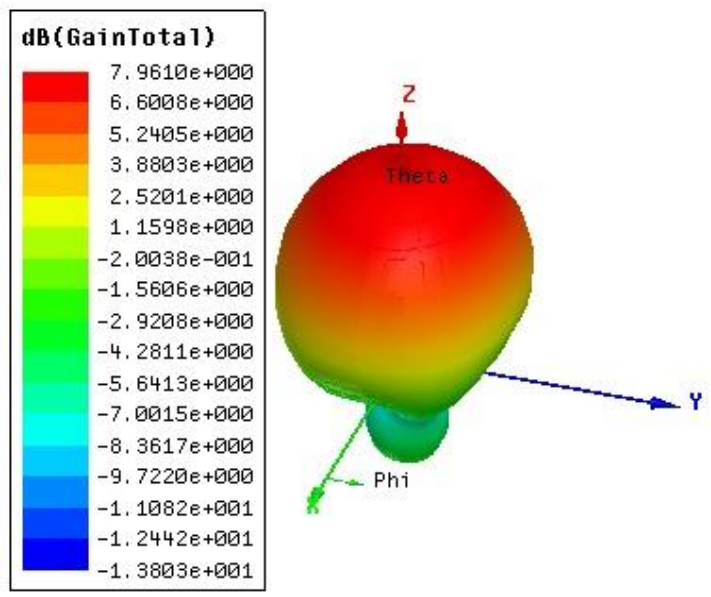

Fig 8: 3D polar plot of Total Gain of simple MPA 


\subsection{Directivity}

Fig. 9 shows the 3D Polar Plot of Total Directivity obtained from I-shaped DGS Antenna. This figure shows that the Total Directivity of the proposed antenna at $\mathrm{f}_{\mathrm{r}}=6.0718$ is $7.92 \mathrm{~dB}$.

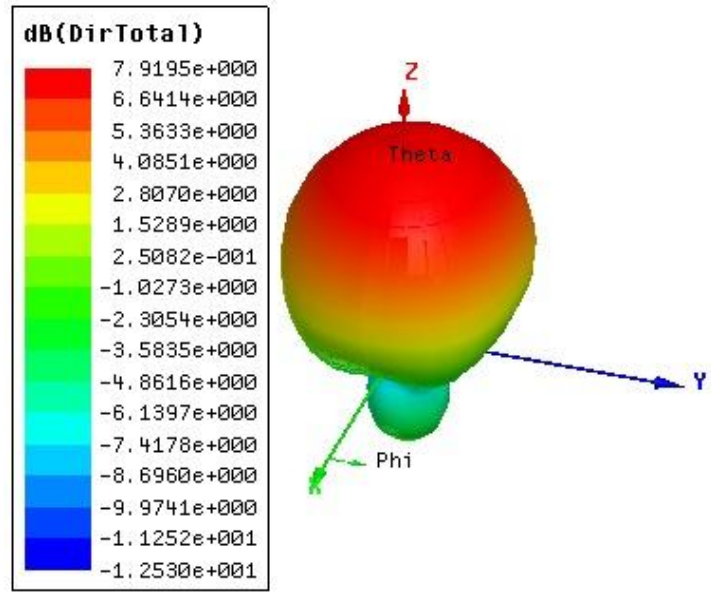

Fig 9: 3D Polar plot of total directivity of I-slot DGS antenna

While the simulated directivity, in case of simple MPA i.e. without defected ground at resonant frequency $\mathrm{f}_{\mathrm{r}}=6.2051$ $\mathrm{GHz}$ is $7.995 \mathrm{~dB}$ as shown in Fig. 10.

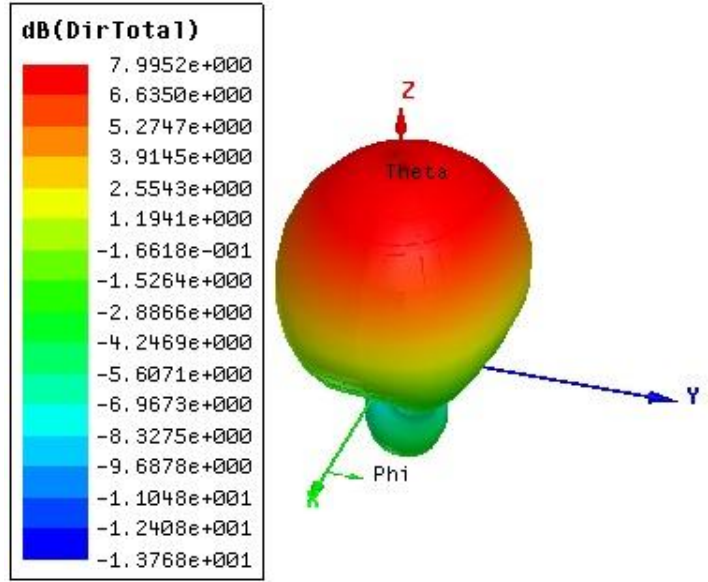

Fig 10: 3D polar plot of total directivity of MPA

Table 2 summarizes the obtained simulation features of the designed antennas.

Table 2. Comparison of simulated results of both antennas

\begin{tabular}{|l|l|c|c|}
\hline $\begin{array}{c}\text { Sr. } \\
\text { No. }\end{array}$ & \multicolumn{1}{|c|}{ Parameters } & $\begin{array}{c}\text { MPA } \\
\text { Antenna }\end{array}$ & $\begin{array}{c}\text { I-Shaped } \\
\text { DGS Antenna }\end{array}$ \\
\hline 1. & $\begin{array}{l}\text { Resonating } \\
\text { Frequency }(\mathrm{GHz})\end{array}$ & 6.2051 & 6.0718 \\
\hline 2. & Bandwidth $(\mathrm{MHz})$ & 126.2 & 132.3 \\
\hline 3. & Return Loss $(\mathrm{dB})$ & -27.72 & -46.75 \\
\hline 4. & VSWR & 1.085 & 1.009 \\
\hline 5. & Gain & 7.96 & 7.91 \\
\hline 6. & Directivity & 7.99 & 7.92 \\
\hline
\end{tabular}

\section{CONCLUSION}

A novel antenna design working in $\mathrm{C}$-band has been successfully implemented in this paper. The bandwidth of the microstrip patch antenna with same dimensions as mentioned above but without slotting is $126.2 \mathrm{MHz}$ at $\mathrm{f}_{\mathrm{r}} 6.2051 \mathrm{GHz}$ with return losses $\left(S_{11}=-27.72 \mathrm{~dB}\right)$ as shown in Fig. 4. While microstrip patch antenna with I-Shape DGS provides bandwidth of $132.3 \mathrm{MHz}$ and return losses reaches up to $46.75 \mathrm{~dB}$ as shown in Fig. 3. Thus it has been concluded that with I-Shape DGS, the bandwidth of the microstrip patch antenna is increased by $6.1 \mathrm{MHz}$. with reduction in ground plane area by $5 \%$.

The proposed antenna design is useful for satellite communications as well as in RADAR.

\section{REFERENCES}

[1] Islam, Mohammad Tariqul, Mohammed Nazmus Shakib, Norbahiah Misran, and Tiang Sew Sun. "Broadband microstrip patch antenna." European Journal of Scientific Research 27, no. 2 (2009): 174-180.

[2] Lo, Terry Kin-chung, and Yeongming Hwang. "Microstrip antennas of very high permittivity for personal communications." In 1997 Asia Pacific Microwave Conference, pp. 253-256. 1997.

[3] Wong, Kin - Lu, and Jin - Sen Chen. "Cavity - model analysis of a slot-coupled cylindrical-rectangular microstrip antenna." Microwave and Optical Technology Letters 9, no. 3 (1995): 124-127.

[4] Chen, Jin - Sen, and Kin - Lu Wong. "Input impedance of a slot - coupled cylindrical - circular microstrip patch antenna." Microwave and Optical Technology Letters 11, no. 1 (1996): 21-24.

[5] Dahele, J. S., R. J. Mitchell, K. M. Luk, and K. F. Lee. "Effect of curvature on characteristics of rectangular patch antenna." Electronics Letters 23, no. 14 (1987): 748-749.

[6] Yablonovitch, Eli. "Inhibited spontaneous emission in solid-state physics and electronics." Physical review letters 58, no. 20 (1987): 2059.

[7] Qu, D., L. Shafai, and A. Foroozesh. "Improving microstrip patch antenna performance using EBG substrates." IEE Proceedings-Microwaves, Antennas and Propagation 153, no. 6 (2006): 558-563.

[8] Jin, Nanbo, Ang Yu, and Xuexia Zhang. "An enhanced $2 \times 2$ antenna array based on a dumbbell EBG structure." Microwave and Optical Technology Letters 39, no. 5 (2003): 395-399.

[9] He, Wei, Ronghong Jin, Junping Geng, and Guoming Yang. " $2 \times 2$ Array with UC - EBG ground for low RCS and high gain." Microwave and optical technology Letters 49, no. 6 (2007): 1418-1422.

[10] Geng, Jun-Ping, Jiajing Li, Rong-Hong Jin, Sheng Ye, Xianling Liang, and Minzhu Li. "The development of curved microstrip antenna with defected ground structure." Progress In Electromagnetics Research 98 (2009): 53-73.

[11] Brown, E. R., C. D. Parker, and Eli Yablonovitch. "Radiation properties of a planar antenna on a photoniccrystal substrate." JOSA B 10, no. 2 (1993): 404-407. 
[12] Radisic, Vesna, Yongxi Qian, Roberto Coccioli, and Tatsuo Itoh. "Novel 2-D photonic bandgap structure for microstrip lines." Microwave and Guided Wave Letters, IEEE 8, no. 2 (1998): 69-71.

[13] Beaky, Matthew M., John B. Burk, Henry O. Everitt, Mansoor A. Haider, and Stephanos Venakides. "Twodimensional photonic crystal Fabry-Perot resonators with lossy dielectrics." Microwave Theory and Techniques, IEEE Transactions on 47, no. 11 (1999): 2085-2091.

[14] Qian, Yongxi, Dan Sievenpiper, Vesna Radisic, Eli Yablonovitch, and Tatsuo Itoh. "A novel approach for gain and bandwidth enhancement of patch antennas." In Radio and Wireless Conference, 1998. RAWCON 98. 1998 IEEE, pp. 221-224. IEEE, 1998.

[15] Wang, Xiaojing, Yang Hao, and Peter S. Hall. "Dualband resonances of a patch antenna on UC-EBG substrate." In Microwave Conference Proceedings, 2005. APMC 2005. Asia-Pacific Conference Proceedings, vol. 1, pp. 4-pp. IEEE, 2005.

[16] Zulkifli, Fitri Yuli, Eko Tjipto Rahardjo, and Djoko Hartanto. "Radiation properties enhancement of triangular patch microstrip antenna array using hexagonal defected ground structure." Progress In Electromagnetics Research M 5 (2008): 101-109.

[17] Arya, A. K., M. V. Kartikeyan, and A. Patnaik. "Efficiency enhancement of microstrip patch antenna with defected ground structure." In Recent Advances in Microwave Theory and Applications, 2008.
MICROWAVE 2008. International Conference on, pp. 729-731. IEEE, 2008.

[18] Zulkifli, Fitri Yuli, Eko Tjipto Rahardjo, and Djoko Hartanto. "Mutual coupling reduction using dumbbell defected ground structure for multiband microstrip antenna array." Progress In Electromagnetics Research Letters 13 (2010): 29-40.

[19] Lin, Xian-Chang, and Ling-Teng Wang. "A wideband CPW-fed patch antenna with defective ground plane." In Antennas and Propagation Society International Symposium, 2004. IEEE, vol. 4, pp. 3717-3720. IEEE, 2004.

[20] Wong, K. L., J. S. Kuo, and T. W. Chiou. "Compact microstrip antennas with slots loaded in the ground plane." In Antennas and Propagation, 2001. Eleventh International Conference on (IEE Conf. Publ. No. 480), vol. 2, pp. 623-626. IET, 2001.

[21] Lin, Shun - Yun, and Kin - Lu Wong. "Effects of slotted and photonic bandgap ground planes on the characteristics of an air - substrate annular - ring patch antenna in the TM21 mode." Microwave and Optical Technology Letters 31, no. 1 (2001): 1-3.

[22] Geng, Jun-Ping, Jiajing Li, Rong-Hong Jin, Sheng Ye, Xianling Liang, and Minzhu Li. "The development of curved microstrip antenna with defected ground structure." Progress In Electromagnetics Research 98 (2009): 53-73 